\title{
CHRONIC AURICULAR TACHYCARDIA
}

\author{
BY \\ R. N. HERSON AND F. L. WILLINGTON
}

From the Department of Medicine, University of Bristol

Received October 12, 1946

There are exceptions to all the criteria employed for the differentiation of paroxysmal auricular tachycardia from other forms of rapid heart action. Nevertheless, the three most constant features are the sudden onset, the short duration (rarely more than ten days), and the sudden termination. We have had the opportunity of observing a case, which while falling into the category of paroxysmal tachycardia, yet differed from the classic type in its chronicity and in its response to treatment.

Case History. A man, aged 31, was admitted to Southmead Hospital on May 27, 1946, with persistent tachycardia. There was no past history of scarlet fever, rheumatism, or diphtheria. A paternal uncle gave a history of bouts of tachycardia since adolescence, lasting anything from minutes to two days.

He was taken prisoner by the Japanese in Bandoeng, Java, on March 8, 1942. As a prisoner he was made to work hard and given poor rations. During 1942 his diet consisted of $400-500 \mathrm{~g}$. of rice daily, a variable quantity of local green vegetables, and an occasional small ration of meat. Later the rice was cut down to about $100 \mathrm{~g}$. a day and was supplemented by an addition of tapioca bread; meat practically disappeared from the diet. During his captivity he had three attacks of bacillary dysentery and dengue once. In 1942, cases of nutritional neuropathy began to occur and were. seen in ever-increasing numbers. He escaped with only slight numbness down both shins, starting two months before release. In September 1945 he was repatriated and had an adequate diet.

During the early part of 1944 he began to get attacks in which he was conscious of his heart beating rapidly and apparently regularly. These attacks lasted about half an hour, and occurred very irregularly. The initial ones stopped spontaneously, and later he learnt to control them by taking a deep breath, leaning forward, and sometimes breaking wind. His medical attendant stopped one attack by carotid pressure.

After he had been subject to these attacks for about six months he found that they persisted longer and were more difficult to terminate. On the ship that brought him back from Singapore in October 1945, some lasted thirty-six hours.

On December 11, 1945, he started an attack of tachycardia, and this was noted by a member of a medical board which discharged him from the Services. He stated that this condition had persisted without interruption ever since. In February 1946 he complained of troublesome dyspnœa on exertion, and this increased rapidly thereafter. His ankles did not swell, and he had no præcordial pain. During the first week in May his doctor sent him for an X-ray, and cardiac enlargement was found, together with pulmonary congestion. $\mathrm{He}$ was ordered to bed and given $15 \mathrm{mg}$. of vitamin $B_{1}$ daily for two weeks with no apparent effect, and subsequently admitted to hospital.

Examination. He was found to be well covered, and was not nervous or distressed. There was no cyanosis of the cheeks or mucous membranes. Dyspnœa occurred on slight exertion but not on lying down. No focal infection was found in the teeth or throat. There 
was no thyroid enlargement, no tremor of the outstretched hands, nor was his skin unduly moist. No abnormality was found on examination of the central nervous system.

The cervical veins were distended, and the liver was enlarged two fingers' breadth below the costal margin. No signs of pulmonary congestion or effusion into serious cavities were found, and there was no œdema. The apex beat was in the sixth intercostal space in the anterior axillary line. No thrills were felt. The heart was beating regularly at the rate of 168 a minute (Fig. 1); the sounds were normal and there were no murmurs. The blood pressure was 105 systolic and 70 diastolic, and showed no postural alteration. Carotid

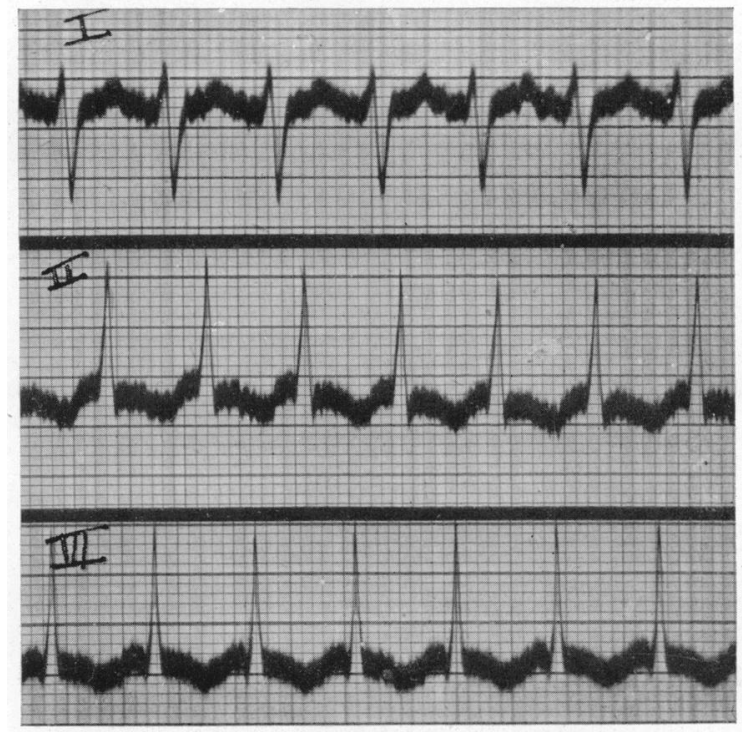

Fig. 1.-Initial cardiogram, May 28, 1946. The three standard leads are shown. The rate is 168 a minute and is regular. $T$ is upright in lead I and inverted in leads II and III.

and eyeball pressure had no effect on the tachycardia, nor was there any alteration with changes of posture, exercise, or phases of respiration.

A teleradiogram showed generalized cardiac enlargement and pulmonary congestion. The hæmoglobin was 108 per cent, the red blood count 5,300,000, and the white blood count 10,200 . The Wassermann reaction was negative. No abnormality was found on examination of the urine. The cardiographic findings, on which a diagnosis of paroxysmal tachycardia was made, will be analysed in a later section.

Progress. Quinidine therapy was attempted and abandoned because he was hypersensitive to small doses.

On June 12 he was given 9 grains of digitalis, and this dosage was continued daily for eleven days, after which it was reduced to 6 grains. On these large doses of digitalis the pulse rate fell during sleep and also showed a gradual decline during the waking hours. On the 27th he complained of nausea and vomiting, and his pulse fell to 80 . Digitalis was discontinued. At this time vagal effects were easily induced. Lying on his left side caused bradycardia, and occasionally even cardiac standstill; both Valsalva's experiment and carotid sinus pressure had the same effect.

On July 4 a cardiogram showed that the rhythm had returned to normal, and his pulse rate was 75 a minute. The cervical veins were no longer distended, and the liver was not 
palpable. A teleradiogram showed that the transverse diameter of the heart was $4 \mathrm{~cm}$. less than on admission.

There was a gradual acceleration of the pulse over the next four days to 150 a minute, with a return of the abnormal rhythm in the cardiogram. Because of the fall of the pulse rate during sleep while on digitalis, it was decided to try and assess the effect of the higher centres in the production of the tachycardia. He was anæsthetized with a small intravenous dose of pentothal, but there was no fall in the pulse rate.

On July 12 he was given $0.5 \mathrm{mg}$. of prostigmine intramuscularly. Fifteen minutes later carotid sinus pressure restored normal rhythm, which persisted only for five minutes. The following day $1 \mathrm{mg}$. of prostigmine was injected and with the help of carotid pressure a short period of cardiac standstill occurred. The ectopic rhythm returned almost at once. Within half an hour toxic effects, in the form of sweating and muscular twitchings, were noted. On the 14th, $1.5 \mathrm{mg}$. tablets of prostigmine were given three times daily, and on this dosage his pulse tended to remain about 130 a minute. In order to augment the effect of the prostigmine $5 \mathrm{~g}$. each of potassium chloride and potassium citrate were given with every dose. This caused severe epigastric pain, sweating, and inability to speak. The dose of potassium salts was reduced by half and this was well tolerated, but appeared to be without effect on the pulse rate, and was, therefore, discontinued.

On July 28 he was started on 1 grain of digitalis, four-hourly, in addition to the prostigmine. By August 7 he complained of diarrhœa, so the dose of digitalis was reduced to three times a day. There followed a period during which the heart rhythm and rate were unstable. Short periods of cardiac standstill were followed by a series of normal beats or by an almost immediate return to the ectopic rhythm. Furthermore, it was found that when he was supine his pulse dropped to 83 ; the rhythm was of sinus origin. On sitting up or standing the ectopic rhythm generally returned and the pulse rose to 120 . These postural effects were gradually lost over the next ten days as the pulse rate slowed to 80 and the rhythm reverted to normal. All treatment was discontinued on August 16. The arrhythmia recurred, and by August 24 the pulse had risen to 160 a minute.

\section{CARDIOGRAPHIC ANALYSIS}

Numerous cardiograms were taken during the period of observation. In the initial curve on May 28, 1946 (Fig. 1) the rate was 168, and there was right axis deviation. It was interpreted as showing paroxysmal tachycardia, although at this stage the possibility of flutter had not been excluded.

On June 21, ten days after starting digitalis, the cardiogram had appreciably altered (Fig. 2). The rate was 145 . An inverted $P$ could be seen in all three leads with a $P-R$ interval of $0.16 \mathrm{sec}$. T wave was upright in lead I and inverted in leads II and III. Inversion of T in leads II and III is well recognized in paroxysmal tachycardia of long duration (Campbell, 1942).

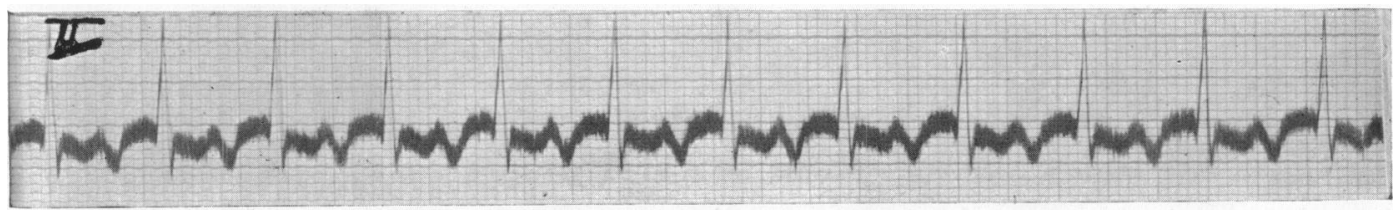

FIG. 2.-Lead II, June 21. The $P-R$ interval is 0.16 sec. The $P$ wave is large and inverted. $T$ is also inverted. This and subsequent cardiograms have been reduced to nine-tenths. 
On June 24 it was found that getting the patient to lie on his left side caused the pulse to become irregular, and even induced sinus block. This is shown in lead II of Fig. 3, in which there is a ventricular extrasystole followed by a normal complex with upright $\mathrm{P}$, and then an ectopic $P$ wave (P1), which failed to excite a ventricular contraction because the conducting tissue was in a refractory state. After $1.2 \mathrm{sec}$. a normal beat followed, and then $0.8 \mathrm{sec}$. later there was another normal beat, the $T$ wave of which was succeeded $0.08 \mathrm{sec}$. later by a series of ectopic beats. In the first of these the P-R interval was 0.28 sec., and in the next

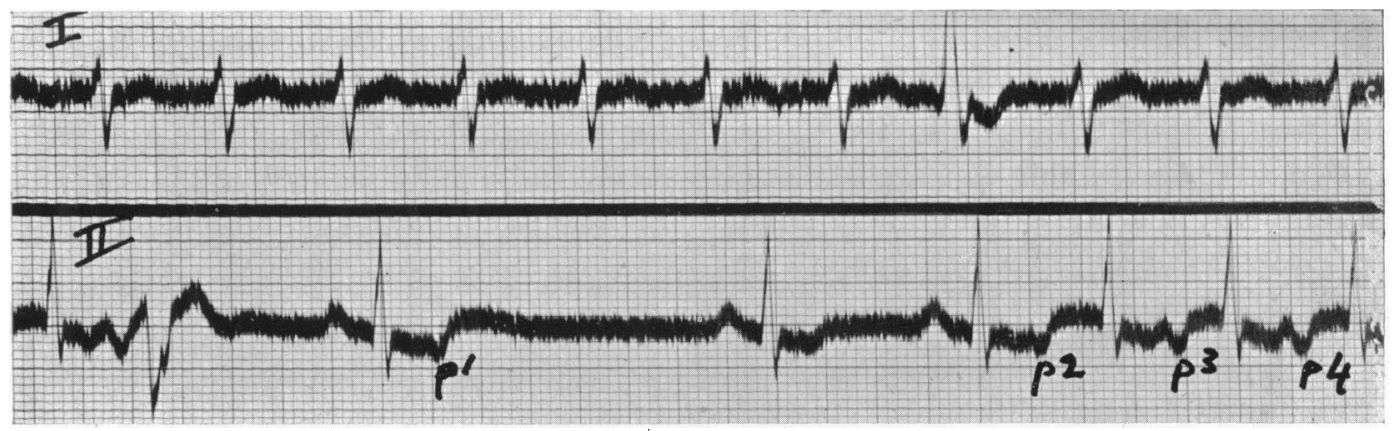

FIG. 3.-Leads I and II, June 24. Lead II shows the effect of lying on the left side while on large doses of digitalis.

0.2 sec. It was considered that the prolongation of the $\mathrm{P}-\mathrm{R}$ interval to $0.28 \mathrm{sec}$. resulted from the premature ectopic impulse reaching the A-V junctional tissue so early that it found it in a relative refractory phase. The distance between P3 and P4 in Fig. 3 is 0.48 sec., and the distance between $\mathrm{P} 1$ and $\mathrm{P} 2$ is $2.4 \mathrm{sec}$., which is five times $0.48 \mathrm{sec}$. This suggests a parasystolic ectopic rhythm of rate 125 a minute. In lead I there was a ventricular extrasystole that did not alter the fundamental rhythm. With continuance of digitalis the P-R interval increased steadily and by June 26 it was 0.24 sec.

On June 28 (when digitalis had been discontinued because of the toxic effects it had produced) a curve was obtained (Fig. 4) which demonstrated increased sensitivity to vagal influence. Lead II showed the end of a long period of sinus block produced by Valsalva's experiment, followed by normal beats with inverted $T$ waves. The shape of the $T$ wave in this, as in other curves, was doubtless influenced by the digitalis which had been administered.

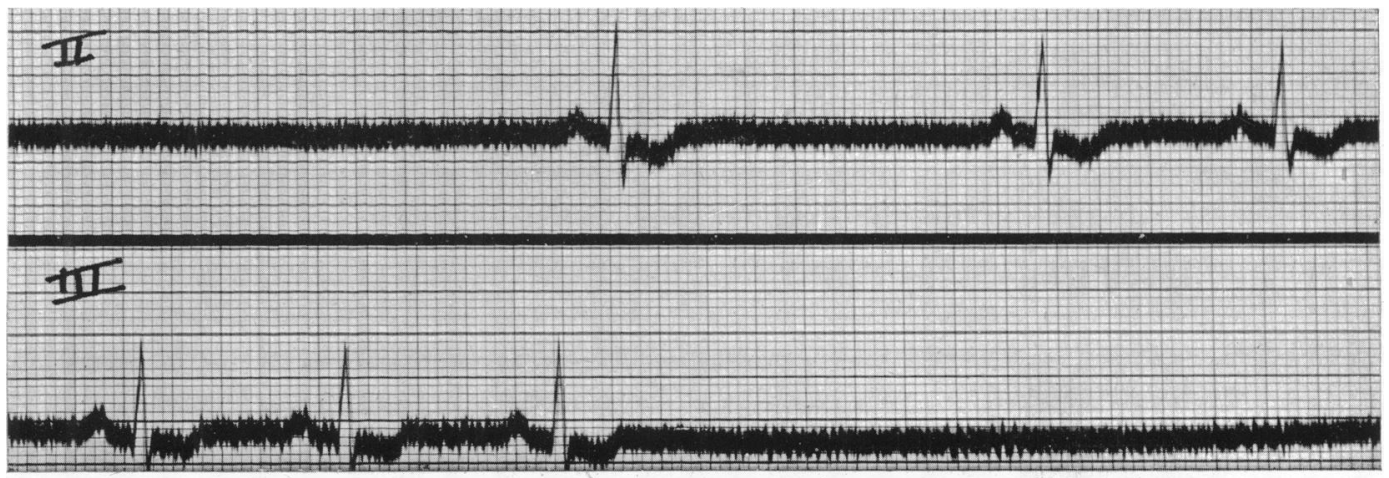

FIG. 4.-Leads II and III, June 28. Lead II shows the effect of Valsalva's experiment. Lead III shows the effect of bilateral carotid sinus pressure. 
Lead III showed the start of another long period of sinus block due to carotid sinus pressure.

The effects of $0.5 \mathrm{mg}$. of prostigmine given on July 18 are seen in Fig. 5. All these curves were taken on lead II. The first one was obtained before the injection, the second after ten minutes, and the third after a further five minutes during bilateral carotid sinus pressure.

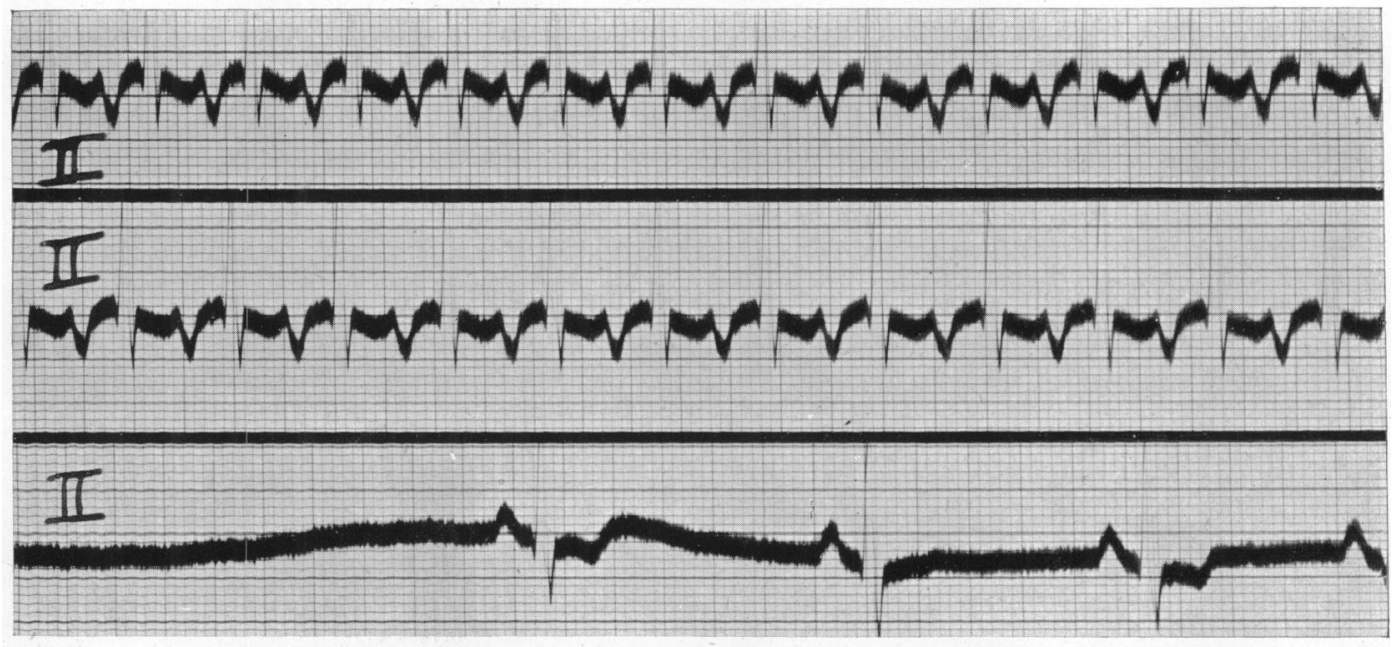

Fig. 5.-July 18. All curves are lead II. The top curve was taken before prostigmine $0.5 \mathrm{mg}$. intramuscularly; the middle, ten minutes after, and the lower with bilateral carotid sinus pressure.

Fig. 6 was obtained on July 4, and shows cessation of the paroxysmal tachycardia. The rate was 75 a minute, and the $P-R$ interval was 0.16 sec. $P$ was upright in all three leads, and $\mathrm{T}$ was inverted in leads II and III.

The præcordial lead CRI was used to study auricular activity. In Fig. 7 the first complex is normal and is followed by an ectopic P which is blocked. There follows, after a pause,

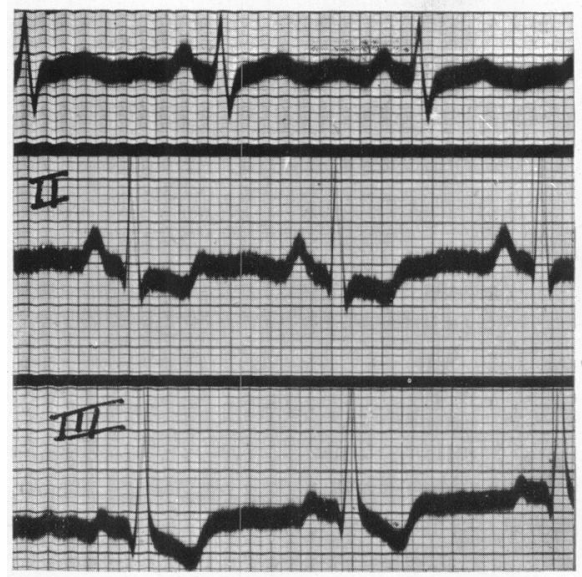

Fig. 6.-Leads I, II, and III, July 4, showing normal rhythm at the rate of 75 beats a minute. The $\mathrm{P}$ waves are upright, and $\mathbf{T}$ is inverted in leads II and III.

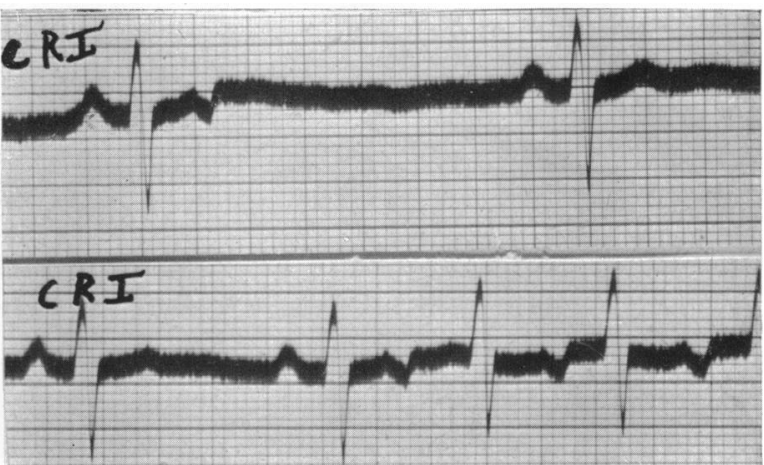

FIG. 7.-Præcordial [lead $\mathbf{C R}_{1}$. A blocked ectopic $\mathbf{P}$ is clearly shown in the first curve. The change-over from normal to ectopic rhythm can be seen in the lower $\therefore$ curve. 
one further normal complex. In the second curve a series of ectopic beats are shown after a normal complex. In neither of these two cardiograms, nor in others, is there evidence of an A-V block.

On August 15 (eighteen days after starting combined prostigmine and digitalis therapy) three cardiograms, each on lead II were taken shortly after $15 \mathrm{mg}$. of prostigmine had been taken by mouth (Fig. 8). In (A) the patient was lying down; a blocked ectopic P (P1) followed the first normal complex, and there followed a long compensatory pause, after which the ventricles responded to an impulse originating in the sino-auricular node. Then followed

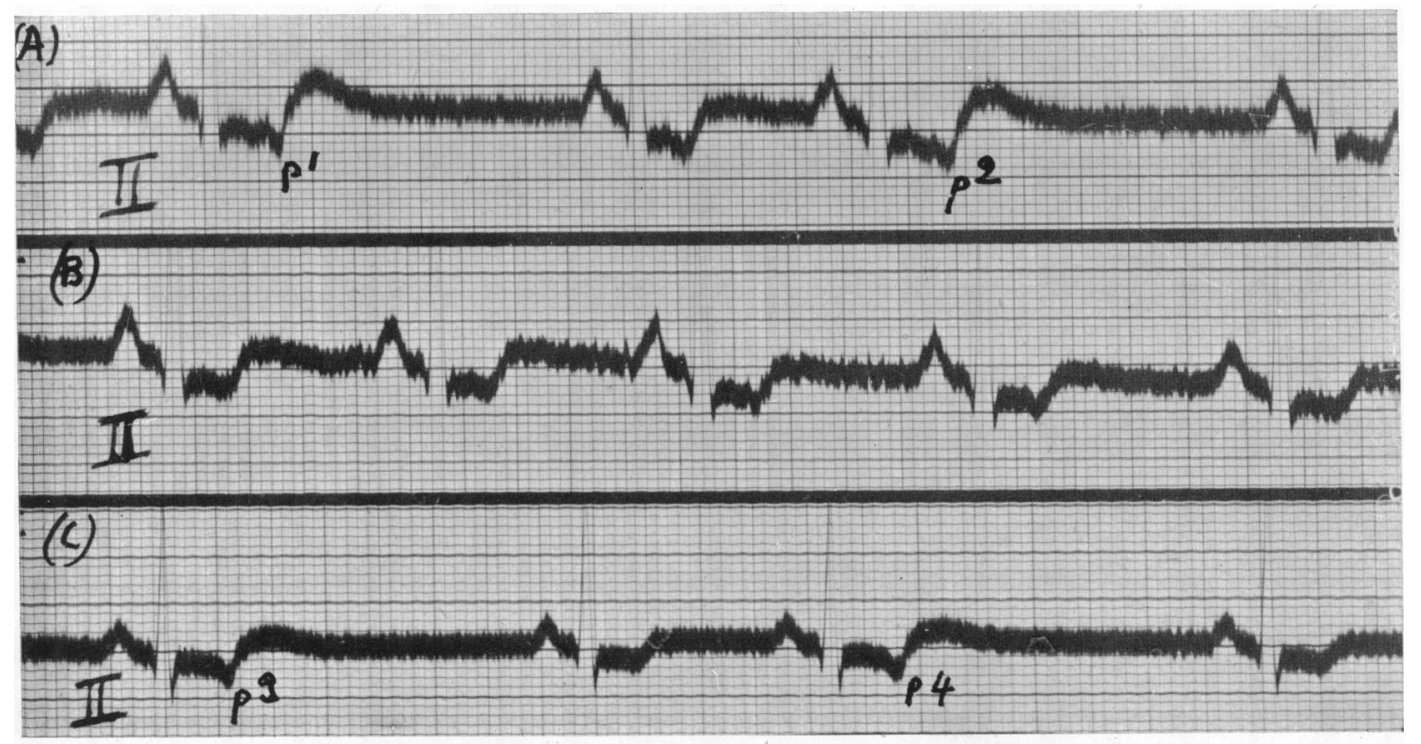

FIG. 8.-August 15. All curves are lead II. (A) was taken lying down; (B) sitting up, and (C) sitting up during bilateral carotid sinus pressure. The curves were taken ten minutes after a $15 \mathrm{mg}$. tablet of prostigmine had been taken by mouth.

(A) and (C) show an ectopic $P$ wave following every second normal complex.

yet another normal beat, and then a second ectopic P (P2) bearing the same relation as $\mathrm{P} 1$ to its preceding QRS. The effect of this grouping was to produce pulsus bigeminus. In (B) the patient was sitting up: the rate was 60 and regular, and the $P-R$ interval was 0.16 sec.; $\mathrm{P}$ was upright and $\mathrm{T}$ inverted. (C) was taken whilst the patient was sitting up, during carotid sinus pressure, and was very similar to (A). This showed that recumbency had an effect on the heart in this case equivalent to direct carotid pressure. The intervals P1, P2, and P3, P4 in Fig. 8 are the same as P1, P2 in Fig. 3 obtained fifty-two days earlier. This finding favours the interpretation of the tachycardia in terms of parasystolic ectopic rhythm.

In the cardiogram ectopic $P$ waves, when following normal complexes, show a fixed relation to them, merging with the preceding $T$, and occur at a time when the junctional tissue is in a relative refractory state. Whether the impulse reaches the ventricle will depend upon the degree of vagal tone. If this is high it will further depress the conductivity and block the impulse. 


\section{Discussion}

Sinus tachycardia can be excluded on the cardiographic evidence of ectopic $\mathrm{P}$ waves. The progressive lengthening of the $\mathrm{P}-\mathrm{R}$ interval produced by large doses of digitalis and also the effects of vagal stimulation during therapy with digitalis or prostigmine do not suggest auricular flutter. Evans (1944) has stressed the importance of the chest lead $\mathrm{CR}_{1}$ for the study of auricular activity. He is of the opinion that by this means a $2: 1 \mathrm{~A}-\mathrm{V}$ block can always be uncovered in paroxysmal tachycardia and that the difference between this condition and flutter is merely the rate of auricular contractions. Campbell (1945) was unable to confirm Evans's findings, as he could exclude an A-V block in at least thirteen of his own sixty-six cases. He considers that the shape of the auricular curves and the presence of an iso-electric level rule out flutter, even if a block can be demonstrated. We could not find an A-V block in any of our tracings in spite of the use of præcordial leads.

The chronicity of the tachycardia and the effects of treatment make this case exceptional. Digitalis produced first a tendency for the pulse to drop during sleep, and then a gradual slowing of the cardiac rate. At one stage, a combination of digitalis and prostigmine made the pulse rate susceptible to change of posture. Each time therapy has been discontinued the arrhythmia has recurred. Classification of this case is especially difficult, because a combination of all these features has seldom been recorded.

Wilson and Hermann's (1923) patient, in whom tachycardia had persisted for fifteen months at the time he was first seen, appeared to be strikingly similar to ours, but refused further treatment before a final result could be obtained; there were similar periods of bradycardia and standstill after digitalization. Maddox (1937) recorded an example of paroxysmal tachycardia lasting at least sixty-nine days in which the attack terminated gradually without the help of digitalis. In his case the pulse slowed spontaneously during sleep. Rest in recumbency for half an hour or more had a similar effect, inducing a $3: 1$ block with a pulse rate of 56, and a conduction time of $0.2 \mathrm{sec}$. With exercise the pulse rose suddenly to 168 while the conduction time remained $0.2 \mathrm{sec}$. He did not specifically investigate the effects of posture on the cardiogram. Attempts to restore normal rhythm with quinidine, digitalis, acetylcholine, adrenaline, and atropine, were unsuccessful. Because of the change of pulse rate with exercise and rest he considered that the extracardiac nerves were mainly responsible. This is of interest in view of the exposure of our patient whilst a prisoner to conditions favouring the production of nutritional neuropathy.

Miller and Perelman (1945) reported two cases of chronic auricular tachycardia, both with aberrant $\mathbf{P}$ waves, which showed striking changes of rate with posture, the rate being slower lying than standing. In their first case posture not only changed the rate but also the direction of the $\mathbf{P}$ wave in lead I. Digitalis abolished the orthostatic acceleration of the pulse rate. In their second case, digitalis did not control the tachycardia and there was no response to quinidine or to potassium salts. This experience led them to recommend that cardiograms should be taken in three positions, standing, sitting, and lying. The importance of this is further emphasized by the reports by Manning and Stewart (1945), and by Holmes and Weill (1945) of the finding of a prolonged P-R interval in healthy young adults, with a decrease to normal on standing. Our case resembles those of Miller and Perelman in its chronicity; the arrhythmia has been present for seven months, and can only be satisfactorily controlled by full doses of digitalis and prostigmine. However, orthostatic phenomena were not present on admission, and were only obtained for short periods just before full therapeutic effect was reached.

The continuous activity of a parasystolic auricular focus with a low degree of exit block under partial control of the extrinsic cardiac nerves, was postulated, though without proof, by Miller and Perelman to explain their findings. Only when it can be shown that the 
intervals between premature systoles from a common focus are equal, or are multiples of a common denominator, and occur without fixed relationship to the beats of sinus origin, can parasystole be diagnosed with confidence. In our case we have been able to show that periods between ectopic beats from a single focus have a common denominator, but the fixed relation of the ectopic beats to beats of sinus origin which can be seen in the cardiograms is a serious obstacle to the acceptance of parasystole. The fixed relationship to the preceding beat may be explained by the theory of re-entry, but Scherf (1929) has produced evidence to show that these extrasystoles are released from an ectopic centre by the preceding normal beat.

\section{SUMMARY}

An unusual case of paroxysmal auricular tachycardia has been described. The abnormal rhythm has persisted for seven months without intermissions, except those produced by treatment. Whatever may be the true explanation of the bizarre features presented by this case it is evident that an ectopic focus has come to dominate the heart, and only when the rate has been slowed, with difficulty, by the action of drugs can the sino-auricular node resume command.

We wish to thank Dr. P. Phillips, Superintendent, Southmead Hospital, Bristol, for permission to publish this case, and Professor C. Bruce Perry, and Dr. C. W. Curtis Bain for their help and advice.

\section{REFERENCES}

Campbell, M. (1942). Brit. Heart J., 4, 49.

(1945), Ibid., 7, 183.

Evans, W. (1944). Ibid., 6, 221.

Holmes, J. H., and Weill, D. R. (1945). Amer. Heart J., 30, 291.

Maddox, K. (1937). Ibid., 14, 183.

Manning, G. W., and Stewart, C. B. (1945). Ibid., 30, 109.

Miller, R., and Perelman, J. S. (1945). Ibid., 29; 555.

Scherf, D. (1929). Z. ges. exper. med., 65, 198.

Wilson, F. N. and Hermann, G. (1923). Arch. intern. Med., 31, 93. 